DOI: $10.15593 / 2224-9354 / 2018.4 .2$

УДК 316.334 .5

\title{
Ю.А. Дроздова
}

\section{ОСНОВНЫЕ МЕТОДОЛОГИЧЕСКИЕ ПОДХОДЫ В ИССЛЕДОВАНИИ РЕГИОНА}

\begin{abstract}
Современный дискурс в исследовании дефиниции «регион» формируется на основе разнообразных научных междисциплинарных подходов, которые изначально детерминируют исследовательский интерес по сферам общественной жизни. Регион рассматривается и как территориальное образование, имеющее четкие административные границы, и как политическое пространство, субъект, часть страны, ее область, и как народно-хозяйственный комплекс, имеющий географрические особенности и природно-ресурсную специализацию, и как экономическая и социальная общность. Управленческий подход определяет регион как «среду управления». Феноменологический и конструктивистский подходы позволяют рассмотреть регион как коммуникативное пространство, где происходит формирование и поддержание региональной идентичности.

Определение региона носит противоречивый, дискуссионный характер в связи со спорностью оснований, предлагаемых различными учеными для определения такой сложной системы, какой является регион, и в связи с «запоздавшим» развитием регионалистики в России. Это объясняется унитарным характером Российского государства и традиционно, исторически сложившимся доминированием политического поля и его акторов, определяющих ракурс территориальных исследований, и недостаточным развитием методов комплексного междисциплинарного подхода.

Автор статьи предлагает рассматривать регион в расширенном и конструируемом смысле как фрормирующийся, изменяющийся, «новый» объект социального управления и социальной реальности. В рамках полипарадигмального социологического подхода автор определяет регион как пространственно-временной континуум, конструируемый социальными взаимодействиями, сетью отношений территориальных общностей - горожан и сельских жителей, социальные ресурсы которых обеспечивают устойчивое развитие и перспективы регионализации.

Ключевые слова: регион, исторический подход, административно-территориальный подход, экономико-географрический подход, социологический подход, региональная идентичность, социальная среда, федерализм, полипарадигмальность, регионализация.
\end{abstract}

Термин «регион» имеет междисциплинарный характер и в зависимости от изучаемой проблемы может использоваться в историческом, правовом, географическом, экономическом или социологическом контексте. До 90-х годов $\mathrm{XX}$ века большинство исследователей региональной проблематики считали экономические функции региона наиболее важными и структурообразующими. В исследованиях региона акцент делался на его объективных характеристиках, к которым относятся: экономико-географическое положение региона, наличие/отсутствие ресурсов, производственная структура, техническая и технологическая оснащенность, емкость рынка, количество и качество трудовых ресурсов.

(С) Дроздова Ю.А., 2018

Дроздова Юлия Алексеевна - канд. социол. наук, доцент кафедры философии и социологии Волгоградского института управления - филиала ФГБОУ ВО «Российская академия народного хозяйства и государственной службы при Президенте Российской Федерации», e-mail: juliadrozdova@mail.ru. 
Данные экономические показатели в первые десятилетия XXI века дополнились такими показателями, как уровень доходов, занятость и рынок труда, жилищные условия, безопасность проживания, демографическая ситуация, экологические и климатические условия, здоровье и уровень образования, социальная инфраструктура. Всего 72 показателя, объединенные в 11 групп, определяющих качество жизни населения, которые уже шестой год используют эксперты рейтингового агентства «РИА Рейтинг» медиагруппы МИА «Россия сегодня» при рейтинге российских регионов [1].

Включение в определение регионов социальных, смысловых показателей, с одной стороны, означает отказ от жестко детерминированного экономического подхода, с другой стороны, обосновывает актуальность и важность определения категории «регион» с позиции современного дискурса, методологического анализа множественных подходов в исследовании региона как сложной социальной системы.

В дискурсе российских междисциплинарных исследований термин «регион» появляется значительно позже, чем в зарубежных. Синонимами данной дефиниции выступали понятия «земля», «край», «зона», «район», «область». Регионалистика в России как новое научное направление появляется достаточно поздно, после распада СССР, в начале 90-х годов XX века, следовательно, запоздавший характер носит институализация ее научного аппарата, терминологии. Создание регионалистики как субдисциплины в этот период являлось сферой интересов государственного управления. Социальные трансформации в России конца XX - начала XXI века обусловили интерес политиков, органов государственного и муниципального управления, исследователей к экономическим, социальным, демографическим, национальным, культурным особенностям определенных территорий, их социальной типологии.

Но интерес к региональной проблематике был связан не только с процессами внутриполитического реформирования России, на его динамику влияют и процессы глобализации социального пространства.

Ряд постулатов различных теорий «глобализации - локализации» свидетельствуют об актуализации региональной проблематики и находят эмпирические подтверждения в региональных исследованиях:

- повышение значимости территориально-географических факторов. Эмпирические исследования автора подтверждают значимость конкретной территории и региональной идентичности для населения регионов России [2, с. 179-180];

- локальность. По определению М. Маклюэна, согласно коммуникационной теории мир представляет «глобальную деревню» [3, с. 71]. На практике именно глобализационные процессы привели к осознанию необходимости сохранения локальной истории, ценностей («глокализации» [4]);

- локализованные проекты развития в условиях глобализации они приобретают безусловное предпочтение как более эффективные и быстроокупаемые. 
Все это в совокупности подчеркивает значение региона как необходимого уровня государственного и межгосударственного управления и актуализирует методологическую рефлексию в его определении.

В связи с обозначенной ретроспективой в становлении регионалистики в России, на наш взгляд, значимость представляет исторический подход, заложивший традицию в исследовании истоков федерализма. Историки были первыми, кто изучал проблемы развития отдельных территорий: в период образования Древней Руси путем слияния земель, княжеств; в период расцвета Киевской Руси, когда в рамках единой государственности сохранялась самостоятельность и автономия отдельных земель, прежде всего, в вопросах внутреннего или местного управления; в период феодальной раздробленности. Сам термин «регион» при этом не использовался, как было описано выше, он возникает значительно позже в научном дискурсе российских исследователей. Но в исследованиях историков Б.А. Рыбакова [5], Н.Я. Данилевского [6] и др. рассматриваются федеративные (даже конфедеративные) истоки российской государственности как уникальные явления в русской государственной унитарной традиции.

Восприятие региона населением страны связано с пассивным принятием государственных замыслов (так было при Петре I в 1708, 1727 годах и Екатерине II в 1775-м), что формирует культуру, мышление как «аспатиальное», т.е. непространственное [7, с. 3]. Данная особенность на многие столетия определила незначительную разработанность концепта «регион» и продолжает зависеть от циклического интереса в исследовании российских регионов.

Исторический подход получил дальнейшее развитие в административно-территориальном подходе. В работах одного из его основоположников Б.Н. Чичерина [8] административно-территориальные единицы («районы»), в отличие от государства, объединены общностью языка или крови, территории, уклада жизни. Данный концепт в тот период, к сожалению, не получил развитие. В работах Х. Ортега-и-Гассета [9], В.Н. Лексина [10], спустя десятилетия, регион будет рассматриваться как социальная идея субъектов управления, ресурсообеспеченных акторов социального пространства, заключающаяся в организации нового типа общественной жизни, взаимодействий в рамках определенных административно-территориальных единиц.

Одним из первых подходов, в рамках которого осуществлялось исследование региона как территории, выделяющейся своими специфическими особенностями, является экономико-географический подход. Первопроходцами, основателями этого подхода можно считать В.Н. Татищева и М.В. Ломоносова, которые не использовали термин «регион», но актуализировали исследование влияния экономических, географических факторов на развитие российских территорий.

Свое развитие данный подход получил в работах Н.Н. Барановского [11], А.И. Зырянова [12]. Авторы данного подхода определяют регион как синоним экономического района, целостную территориальную часть народного 
хозяйства страны, имеющую свою специализацию, прочные внутренние экономические связи. Но в работах советских ученых, как отмечал А. Гранберг, доминировал экономоцентрический подход: «В целом проблематика типовых региональных исследований в СССР соответствовала требованиям расширяющейся экономики на стадии индустриализации с преобладанием экстенсивных факторов роста» [13, с. 77].

В 90-е годы XX века процесс федерализации позволил отойти от жесткой иерархии: «экономическое - социальное», и регион стали рассматривать как относительно самостоятельное образование, природа которого определяется экономическими, социальными, природными, культурными и другими факторами, что возродило междисциплинарные исследования региона и обусловило появление новых научных подходов.

Свое развитие междисциплинарный экономико-географический подход, но с акцентированием внимания на социальных аспектах, получил в работах Н.В. Зубаревич [14], которая в режиме мониторинга осуществляла исследование социально-экономического развития регионов. Она отмечает «мощную инерцию российского пространства» $[14$, с. 1], слабую восприимчивость к инновациям, слабую инвестиционную привлекательность большинства провинциальных российских регионов. Н.В. Зубаревич также отмечает взаимозависимость и взаимовлияние экономических, политических и социальных характеристик региона, констатируя на сегодняшний день укрепление властной вертикали, усиление централизации, подчинение региональных, муниципальных интересов государственным, отказ от политики регионализации России. В современных условиях происходит поворот к контролю социальных ресурсов территориальных общностей, в том числе через ужесточение политики по отношению к малому бизнесу, еще большая зависимость муниципальных бюджетов от региональных, а региональных, в свою очередь, от федерального; использование «джерримендеринга» на муниципальных выборах, позволяющего выдвинуть на местном уровне кандидатуру, удобную для региональных/федеральных властей.

Регион с позиции данного подхода становится объектом манипуляции политических субъектов, что ограничивает возможности в развитии социальных ресурсов территориальных общностей. В современных условиях можно говорить о негативных траекториях в развитии российских регионов, что актуализирует исследование социальных ресурсов территориальных общностей.

Большую ценность в связи с этим представляют научные подходы, которые акцентируют внимание на социальных, культурных, аксиологических и других аспектах.

Регион в геокультурном подходе (Б. Верлен [15], Д.Н. Замятин [16] и др.) рассматривается как геокультурное, аксиологическое пространство, целостная система устойчивых культурных реалий, представлений, этнолингвистических особенностей, элементов жизни на определенной территории. По мнению 
Б. Верлена, «пространственные и временные компоненты, действия не детерминированы только географическими факторами, география представляет лишь схемы, объясняющие размещение объектов» [15, с. 34]. Восприятие пространства предполагает восприятие традиций, культуры, сложившейся на определенной территории. Основным элементом в данном подходе является сама территория как определенная целостность, а географические образы пространства становятся частью мировоззрения, определенными ценностями, маркерами социальной общности, к которой мы принадлежим, проживая на определенной территории.

Регион впервые стал рассматриваться как пространственно-территориально-символический феномен, обозначаемый через географические понятия «земля» и «край», которые наполняются новым содержанием, в том числе «малая родина», «наша земля», анализ которых будет осуществлен в рамках сочиокультурного подхода.

В социокультурном подходе регион определяется как «культурный ландшафт» и «особый мир» [17] с присущим только ему менталитетом, образом мышления, традициями. Культурные артефакты, по мнению зарубежных и отечественных исследователей, определяют матрицу взаимодействий индивидов. Именно данная матрица (язык, мифы, история, традиции, ритуалы, нормы, правила, социальные ценности) как «идеальный тип» позволяет соотнести индивида с определенной территориальной общностью. Это соотнесение, выстраивание общностной идентичности обеспечивает устойчивую сеть социальных отношений, формирует единое смысловое пространство, определяемое как «культурный регион». Несогласованность и противоречивость ценностной составляющей взаимодействующих носителей культуры может нарушить целостность региона как системы, затруднять формирование и развитие социальных ресурсов региона. Можно считать данный подход базовым в исследовании социальных ресурсов территориальных общностей горожан и сельских жителей.

Свое развитие дефиниция «регион» как более совершенная форма системной организации с относительной автономностью, но и взаимозависимостью сложных, высокоорганизованных систем и подсистем получила в рамках синергетического подхода (Г. Хакен [18]. И.Р. Пригожин [19] и др.). В контексте синергетического подхода появляется концепт «жизненной энергии» региона, населения, который позволяет раскрыть специфику использования различных социальных ресурсов территории с учетом эмоционального, умственного и физического состояния человека, «его способности ставить перед собой значимые цели и совершать те или иные социальные действия» [20, с. 108].

На наш взгляд, превращение потенциальных возможностей региона в ресурсы, их капитализация происходят только при условии их востребованности региональными субъектами (территориальными общностями) во взаимодействиях и практиках освоения социального пространства и времени, что актуализирует исследование региона с позиции социологического подхода. 
Социологическое направление в исследовании региона представлено множеством теоретических подходов. Так, регион как сложноструктурированная социальная система исследуется в работах А.Г. Гранберга [13], Н.И. Лапина [21], Н. Лумана [22]. Категория региона в системном подходе рассматривается как автономная, самостоятельная система, но система иного уровня по сравнению с обществом [23, с. 348-350]. Регион как система мезоуровня в своем составе имеет отдельные организованные по определенным признакам социальные системы, такие как поселения, общины, деревни, округа, города и районные центры, позволяющие рассматривать их как территориальные общности.

Четыре основные функции региона, проанализированные Н.И. Лапиным: жизнеобеспечивающая, духовно-интегрирующая, статусно-дифференцирующая, властно-регулирующая, - обеспечивают встраивание определенных территорий в пространство страны, взаимодействия на внутригосударственном и иных уровнях. При этом, как неоднократно подчеркивал Н.И. Лапин, «статус регионов в российском обществе остается рыхлым и противоречивым» [21, с. 30].

В контексте исследования социальных ресурсов территориальных общностей мы акцентируем внимание, прежде всего, на качественных характеристиках региона, которые не стали пока предметом глубокой научной рефлексии. Среди качественных характеристик региона, согласно авторскому концепту рассмотрения региона как пространственно-временного континуума, мы выделяем следующие:

- открытость и динамичность, обеспеченную сетью социальных отношений, взаимодействий, в том числе и виртуальных;

- многоуровневость (внешние, внутренние связи, межрегиональные, межгосударственные);

- специфичность, определяемую в том числе социальными ресурсами региона (история, имидж, человеческие ресурсы, символы, социальный капитал и т.д.);

- устойчивость, возникающую при использовании во времени (прошлое настоящее - будущее) региональных ресурсов, среди которых социальные ресурсы являются основными и восполняемыми;

- инерционность, охарактеризованную еще в рамках ограниченного экономического подхода, и реанимирующую субъектами управления, в том числе в системе отношений «Центр - регион».

Данный ракурс рассмотрения региона частично получит развитие в рамках управленческого подхода. Регион можно рассмотреть как среду управления, представляющую собой совокупность материальных, экономических, социальных, политических и духовных условий существования, формирования и деятельности индивидов и социальных групп на определенной территории, изменяющуюся в процессе государственного и регионального управления.

Анализ региональной среды управления (макро-, микросреды) позволяет выявить ее типологию: инертная, оптимальная и агрессивная. Инертная 
региональная среда управления диагностируется в большинстве провинциальных российских регионов, характеризуется низкой социальной активностью социальных субъектов, апатичным и лишенным инициативы социальным поведением и может являться реакцией на социальные изменения, кризис и «социальную травму» $[24$, с. 6$]$.

Регион как среда управления, следовательно, в зависимости от типа взаимодействий и социальных отношений, поведенческих стратегий членов территориальных общностей приобретает также различные социальные характеристики.

Социологическое направление в исследовании региона получило развитие в пост/неомодернистских концепциях Ж. Бодрийяра [25], 3. Баумана [26], П. Бурдье [27]. Среди отечественных исследователей понятие «регион» привлекает внимание Г.Е. Зборовского, который рассматривает соотношение понятий «регион» и «социальное пространство», определяя первое как «региональное социальное пространство, характеризующееся взаимодействием в нем определенных социальных общностей» [28, с. 17].

Данный концепт находит отражение в феноменологических, коммуникативных и конструктивистских социологических подходах, учитывает взаимосвязи и взаимозависимости деятельности, социальных отношений, взаимодействий территориальных общностей, что является принципиально важным для авторского определения региона. Регион мы рассматриваем как пространственно-временной континуум, который образуется потоком событий, конструируемых взаимодействующими агентами - представителями территориальных общностей, среди которых мы выделяем как особо значимые общности горожан и сельских жителей. Социальные взаимодействия, социальные отношения, взаимосвязи и взаимозависимости в современных условиях во времени претерпевают постоянные трансформации (централизация регионализация, глобализация - глокализация, информатизация, миграция и другие социальные изменения). Но они всегда опосредованы физическим пространством с распознаваемым местоположением, включающим пространство социальное. Пространственно-временной континуум отражает процессуальный характер существования региона.

Регион, с одной стороны, определяет условия жизнедеятельности социальных общностей, которые являются высшей ценностью в регионе, с другой стороны, формируется, развивается, благодаря освоению и воспроизводству социальных ресурсов на определенной территории.

Регион как носитель определенных социальных ресурсов включает в себя количественные и качественные показатели. Количественные показатели определяются численностью населения, динамикой, интенсивностью демографических процессов, урбанизацией, миграцией, национально-религиозным составом населения, социальной стратификацией, экономическим статусом региона. К качественным показателям региона мы относим пространство и время, имидж 
региона, региональную идентичность, ценности и смыслы, качество социальных связей (социальный капитал) и человеческие ресурсы.

Развитие методологической рефлексии предполагает исследование региона как пространственно-временного континуума, обеспеченного воспроизводством социальных ресурсов и новыми смыслами взаимодействия и самореализации на данной территории представителями социальных общностей горожан и сельских жителей. Данное исследование обеспечивает социологическую рефлексию для определения траектории развития региона и перспективы регионализации.

\section{Список литературы}

1. Названы лучшие и худшие по качеству жизни регионы России [Электронный ресурc]. - URL: https://mir24.tv/news/15733368/nazvany-luchshie-ihudshie-po-kachestvu-zhizni-regiony-rossii (дата обращения: 25.03.2018).

2. Дроздова Ю.А. Дискурсы повседневности и аффектов в тексте регионального пространства (на примере Волгоградской области) // Вестник Московского государственного университета. Серия 18. Политология и социология. - 2016. - № 3. - С. 175-192.

3. Маклюэн М. Галактика Гуттенберга: Становление человека печатающего / пер. И.О. Тюриной. - М.: Гаудеамус, Академический проект, 2005. - 496 с.

4. Robertson Roland. Globalization: Social Theory and Global Culture (Theory, Culture \& Society Series). - SAGE Publications. Printed in GreatiSritain by The Cromwell Press Ltd, Broughton Gifford, Melksham, Wiltshire, 1992. - 211 p.

5. Рыбаков Б.А. Киевская Русь и русские княжества XII-XIII веков. М.: Наука, 1982. -592 с.

6. Данилевский Н.Я. Россия и Европа. - М.: Институт русской цивилизации, 2008. - $816 \mathrm{c}$.

7. Смирнягин Л.В. Российский федерализм: парадоксы, противоречия, предрассудки. - М.: Московский общественный научный фонд, 1998. № $63 .-72 \mathrm{c}$.

8. Чичерин Б.Н. Курс государственной науки. - Т. I-III. - М.: Типография товарищества И.Н. Кушнерев и Ко, 1894. - 1479 с.

9. Ортега-и-Гассет Х. Избранные труды. - М.: Весь мир, 1997. - 704 с.

10. Лексин В.Н. Федеративная Россия и ее региональная политика. - М.: ИНФРА-М, 2008. - $352 \mathrm{c.}$

11. Барановский Н.Н. Избранные труды. Становление советской экономической географии. - М.: Мысль, 1980. - 287 с.

12. Зырянов А.И. Регион: пространственные отношения природы и общества / Перм. гос. техн. ун-т. - Пермь, 2006. - 372 с.

13. Гранберг А.Г. Основы региональной экономики: учеб. для вузов. М.: Изд. дом ГУ ВШЭ, 2004. - 495 с. 
14. Зубаревич Н.В. «Бремя регионов»: что изменилось за десять лет? // Контрапункт. - 2016. - № 6. - С. 1-9.

15. Верлен Б. Общество, действие и пространство. Альтернативная социальная география// Социологическое обозрение. - 2001. - Т. 1, № 2. - С. 25-46.

16. Замятин Д.Н. Культура и пространство. Моделирование географических образов. - М.: Знак, 2006. -488 с.

17. Бродель Ф. Материальная цивилизация, экономика и капитализм. XV-XVIII вв. Структуры повседневности: возможное и невозможное. - М.: Прогресс, 1986. - Т. 1. -620 с.

18. Хакен Г. Информация и самоорганизация. Макроскопический подход к сложным явлениям. - М.: Мир, 1991. - 240 с.

19. Пригожин И. Философия нестабильности // Вопросы философии. 1991. - № 6. - С. 46-52.

20. Немировский В.Г., Немировская А.В. Жизненная энергия и другие ресурсы социальных субъектов (на материалах социологических исследований в Красноярском крае)// Мониторинг общественного мнения. - 2014. № 4(122). - С. 104-118.

21. Лапин Н.И. Регион, его статус и функции в российском обществе: теоретико-методологические основы исследования // Социологические исследования. - 2006. - № 8. - С. 25-34.

22. Луман Н. Общество как социальная система. - М.: Логос, 2004. - 232 с.

23. Шилз Э. Общество и общества: макросоциологический подход // Американская социология: перспективы, проблемы, методы. - М.: Прогресс, 1972. - C. 341-359.

24. Штомпка П. Социальные изменения как травма // Социологические исследования. -2001 . - № 1. - С. 6-17.

25. Бодрийяр Ж. В тени молчаливого большинства, или Конец социальности вещей. - Екатеринбург, 2000. - 96 с.

26. Бауман 3. Глобализация. Последствия для человека и общества: пер. с англ. - М.: Весь Мир, 2004. - 188 с.

27. Bourdieu P. Sozialer Raum und Klassen. - Frankfurt am Main: Leçon sur la lecon, Suhrkamp, 1985. - 82 p.

28. Зборовский Г.Е. Региональное социальное пространство как социологический феномен // Социум и власть. - 2010. - № 4 (28). - С. 11-20.

\section{References}

1. Nazvany luchshie i khudshie po kachestvu zhizni regiony Rossii [Best and worst regions of Russia in terms of living conditions], available at: https://mir24.tv/ news/15733368/nazvany-luchshie-i-hudshie-po-kachestvu-zhizni-regiony-rossii (accessed 25 March 2018). 
2. Drozdova Iu.A. Diskursy povsednevnosti i affektov v tekste regional'nogo prostranstva (na primere Volgogradskoi oblasti) [Discourses of routine and affects in the text of regional space (on the example of Volgograd region)]. Vestnik Moskovskogo gosudarstvennogo universiteta. Seriia 18. Politologiia i sotsiologiia, 2016, no. 3, pp. 175-192.

3. MacLuhan M. The Gutenberg Galaxy: The making of typographic man [Russ. ed.: Makliuen M. Galaktika Guttenberga: Stanovlenie cheloveka pechataiushchego. Moscow, Gaudeamus, Akademicheskii proekt, 2005, 496 p.].

4. Robertson R. Globalization: Social theory and global culture (Theory, culture \& society series). SAGE Publications, 1992, 211 p.

5. Rybakov B.A. Kievskaia Rus' i russkie kniazhestva XII-XIII vekov [The Kievan Rus' and Russian principalities of the $12^{\text {th }}-18^{\text {th }}$ centuries]. Moscow, Nauka, 1982, $592 \mathrm{p}$.

6. Danilevskii N.Ia. Rossiia i Evropa [Russia and Europe]. Moscow, Institut russkoi tsivilizatsii, 2008, $816 \mathrm{p}$.

7. Smirniagin L.V. Rossiiskii federalizm: paradoksy, protivorechiia, predrassudki [Russian federalism: paradoxes, controversies, stereotypes]. Moscow, Moscow Public Scientific Fund, 1998, vol. 63, 72 p.

8. Chicherin B.N. Kurs gosudarstvennoi nauki [A course in the art of state management]. Vol. I-III. Moscow, Tipografiia tovarishchestva I.N. Kushnerev i Ko, 1894, 1479 p.

9. Ortega y Gasset H. Selected works [Russ. ed.: Ortega-i-Gasset Kh. Izbrannye trudy. Moscow, Ves' mir, 1997, 704 p.].

10. Leksin V.N. Federativnaia Rossiia i ee regional'naia politika [Federal Russia and its regional policy]. Moscow, INFRA-M, 2008, 352 p.

11. Baranovskii N.N. Izbrannye trudy. Stanovlenie sovetskoi ekonomicheskoi geografii [Selected works. Rising of Soviet economic geography]. Moscow, Mysl', $1980,287 \mathrm{p}$.

12. Zyrianov A.I. Region: prostranstvennye otnosheniia prirody i obshchestva [A region: Spatial relations between nature and society]. Perm, Perm State Technical University, 2006, $372 \mathrm{p}$.

13. Granberg A.G. Osnovy regional'noi ekonomiki [Fundamentals of regional economy]. Moscow, Higher School of Economics, 2004, 495 p.

14. Zubarevich N.V. "Bremia regionov": chto izmenilos' za desiat' let? [The burden of regions: what's changed in ten years?]. Kontrapunkt, 2016, no. 6, pp. 1-9.

15. Verlen B. Obshchestvo, deistvie i prostranstvo. Al'ternativnaia sotsial'naia geografiia [Society, action and space. An alternative social geography]. Sotsiologicheskoe obozrenie, 2001, vol. 1, no. 2, pp. 25-46.

16. Zamiatin D.N. Kul'tura i prostranstvo. Modelirovanie geograficheskikh obrazov [Culture and space. Modeling geographic images]. Moscow, Znak, 2006, 488 p. 
17. Braudel F. Civilization and Capitalism, $15^{\text {th }}-18^{\text {th }}$ century. Vol. 1 [Russ. ed.: Brodel' F. Material'naia tsivilizatsiia, ekonomika i kapitalizm. XV-XVIII vv. Tom 1. Struktury povsednevnosti: vozmozhnoe i nevozmozhnoe. Moscow, Progress, 1986,620 p.].

18. Haken H. Information and self-organization: A macroscopic approach to complex systems [Russ. ed.: Khaken G. Informatsiia i samoorganizatsiia. Makroskopicheskii podkhod k slozhnym iavleniiam. Moscow, Mir, 1991, 240 p.].

19. Prigozhin I. Filosofiia nestabil'nosti [Philosophy of instability]. Voprosy filosofii, 1991, no. 6, pp. 46-52.

20. Nemirovskii V.G., Nemirovskaia A.V. Zhiznennaia energiia i drugie resursy sotsial'nykh sub"ektov (na materialakh sotsiologicheskikh issledovanii v Krasnoiarskom krae) [Life energy and other resources of social subjects (based on the data of sociological studies conducted in Krasnoyarsk region)]. Monitoring obshchestvennogo mneniia, 2014, no. 4(122), pp. 104-118.

21. Lapin N.I. Region, ego status i funktsii $\mathrm{v}$ rossiiskom obshchestve: teoretiko-metodologicheskie osnovy issledovaniia [A region, its status and function in Russian society: theoretical and methodological bases of research]. Sotsiologicheskie issledovaniia, 2006, no. 8, pp. 25-34.

22. Luhmann N. Social systems [Russ. ed.: Luman N. Obshchestvo kak sotsial'naia sistema. Moscow, Logos, 2004, 232 p.].

23. Shils E. On the constitution of society [Russ. ed.: Shilz E. Obshchestvo i obshchestva: makrosotsiologicheskii podkhod. Amerikanskaia sotsiologiia: perspektivy, problemy, metody. Moscow, Progress, 1972, pp. 341-359].

24. Sztompka P. Sociological dilemmas [Russ. ed.: Shtompka P. Sotsial'nye izmeneniia kak travma. Sotsiologicheskie issledovaniia, 2001, no. 1, pp. 6-17].

25. Baudrillard J. In the shadow of the silent majorities [Russ. ed.: Bodriiiar Zh. $\mathrm{V}$ teni molchalivogo bol'shinstva, ili konets sotsial'nosti veshchei. Yekaterinburg, 2000, 96 p.].

26. Bauman Z. Globalization: The Human Consequences [Russ. ed.: Bauman Z. Globalizatsiia. Posledstviia dlia cheloveka i obshchestva. Moscow, Ves' Mir, 2004, 188 p.].

27. Bourdieu P. Sozialer Raum und Klassen. Frankfurt am Main, Lȩon sur la leçon, Suhrkamp, 1985, $82 \mathrm{p}$.

28. Zborovskii G.E. Regional'noe sotsial'noe prostranstvo kak sotsiologicheskii fenomen [Regional social space as a sociological phenomenon]. Sotsium $i$ vlast', 2010, no. 4 (28), pp. 11-20.

Оригинальность $84 \%$

Получено 16.05.2018 Принято 04.06.2018 Опубликовано 28.12.2018 


\section{Yu.A. Drozdova}

\section{GENERAL METHODOLOGICAL APPROACHES TO REGION STUDIES}

The modern discourse in the study of region definition stems from diverse interdisciplinary approaches that initially condition researchers' interest in differing social areas. A region is regarded as a territorial entity with clear-cut administrative borders, and as a political space, as a part of the country, as an entity in national economy with its geographic features and specialization based on chosen natural resources, and, finally, as an economic-social community. The managerial approach defines a region as a medium of management. Phenomenology and constructivism allow an understanding of a region as a communication space where regional identity develops and is maintained.

Definition of a region shows a controversial, speculative nature since the grounds on which researchers base their views on such a complex phenomenon are debatable; besides, region studies in Russia are of recent vintage. This is due to the unitary nature of the Russian state, the predominance of the political field and its actors that determine the research perspective, and due to insufficient development of the methods of a complex interdisciplinary approach.

The author suggests to treat a region with a broader, anticipatory interpretation as an emerging, evolving, 'novel' object of social management and social reality. In the framework of multi-paradigmal sociological approach the author defines a region as a spatial and temporal continuum constructed from social interactions, a network of relations between urban and country dwellers whose social resources ensure a sustainable development and regionalization prospects.

Keywords: region, historical approach, administrative and territory-based approach, economic and geographic approach, sociological approach, regional identity, social environment, federalism, multi-paradigmal approach, regionalization.

Yuliya A. Drozdova - Candidate of Sociological Sciences, Associate Professor, Department of Philosophy and Sociology, Volgograd Institute of Management - branch of Russian Presidential Academy of National Economy and Public Administration under the President of the Russian Federation, e-mail: juliadrozdova@mail.ru.

Received 16.05.2018 Accepted 04.06.2018 Published 28.12.2018 